\title{
Comparative study of community acute kidney injury in young patients versus elderly patients in an internal medicine department in Abidjan (Côte d'Ivoire)
}

\author{
Kouamé Hubert Yao ${ }^{*}$, Monlet Cyr Guei ${ }^{2}$, Weu Melanie Tia ${ }^{2}$, Serge Didier Konan ${ }^{1}$, Séry Patrick Diopoh ${ }^{1}$, \\ Sindou Sanogo ${ }^{1}$ \\ ${ }^{1}$ Department of Nephrology and Internal Medicine, University Hospital of Treichville, Abidjan, Côte d'Ivoire \\ ${ }^{2}$ Department of Nephrology University Hospital of Yopougon, Abidjan, Côte d'Ivoire
}

\section{A R T I C L E IN F O}

Article Type:

Original

\section{Article History:}

Received: 4 July 2016

Accepted: 20 November 2016

Published online: 20 December 2016

\section{Keywords:}

Acute kidney injury

Elderly patient

Young patient

Infection

\begin{abstract}
A B S T R A C T
Introduction: Numerous studies have shown that the recovery of renal function was slower and less complete in the elderly patients than in adults.

Objectives: To compare the profile of acute kidney injury (AKI) of the young patients with that of the elderly patients.

Patients and Methods: This is a prospective study carried out during the period from January 2010 to December 2015 in the department of Nephrology-Internal Medicine of the University hospital of Treichville. The diagnosis of AKI was retained according to Kidney Disease: Improving Global Outcomes (KDIGO) criteria.

Results: The mean age of patients was $26.8 \pm 6$ years in the young and $69.4 \pm 7$ years in the elderly. The proportion of males was $51.9 \%(55 / 106)$ in the young patients against $77.8 \%$ $(84 / 108)$ in the elderly patients $(P=0.0001)$. The proportion of hypertension and diabetes in the elderly patients, respectively $30.6 \%$ and $36.1 \%$ was statistically higher than in the young patients $(P=0.001)$. However, human immunodeficiency virus $(\mathrm{HIV})$ infection was more prevalent in the young patients $(P=0.0001)$. Anemia was observed in $84.9 \%$ in the young patients against $58.3 \%$ in the elderly patients $(P=0.001)$. It was severe in $34 \%$ among the young patients against $15.7 \%$ among the elderly patients $(P=0.002)$. The proportion of drug AKI was $17 \%$ in the young patients against $2.8 \%$ in the elderly patients $(P=0.0001)$. Malignant hypertension $(P=0.002)$ and urinary tract tumors $(P=0.001)$ were more observed in the elderly patients. Mortality was $31.1 \%$ in the young patients against $47.2 \%$ in the elderly patients $(P=0.011)$.

Conclusion: The etiologies are the same with different proportions, except malignant hypertension observed only in the elderly patients. Mortality is higher in the elderly patients.
\end{abstract}

Implication for health policy/practice/research/medical education:

In our study, we found that regardless of age, infection is the leading cause of acute kidney injury (AKI). Drug-induced AKI is more common in young adults. On the other hand, benign tumor of the urinary tract and malignant hypertension are more found in the elderly. In addition, mortality and non-recovery of renal function are higher in the elderly. The causes of death and the factors associated with mortality and non recovery of renal function differ in both groups.

Please cite this paper as: Yao KH, Guei MC, Tia WM, Konan SD, Diopoh SP, Sanogo S. Comparative study of community acute kidney injury in young patients versus elderly patients in an internal medicine department in Abidjan (Côte d'Ivoire). J Renal Inj Prev. 2017;6(3):199-204. DOI: 10.15171/jrip.2017.38.

\section{Introduction}

Acute kidney injury (AKI) is characterized by a sudden drop in glomerular filtration rate. It is commonly seen in our medical practice. Its incidence varies from $1.9 \%$ to $24.4 \%$ depending on the series (1-4). In intensive care units, this incidence is in the order of $20 \%$ to $50 \%$ (5). The etiologies of AKI vary from one region to the other of the world. In the West countries, septic shock, hyopovolemia, cardiogenic shock and post-operative AKI are the most common in adults (4). In Africa, the 
causes are dominated by infections, toxic and obstetric gynecology causes are responsible (6).

AKI may occur at any age. If chronic kidney diseases (CKDs), related to polypharmacy and renal manifestations of chronic diseases are common among the elderly patients, AKI is a reality in this population. The etiologies of AKI among the elderly patients seem to be the same in the general population. Only the distribution seems different with a higher proportion of obstructive AKI (2). The mortality of patients with AKI is worrisome, since it remains high despite the progress of methods of dialysis and resuscitation (2,3). Regarding renal survival, studies have shown that the recovery of renal function was slower and less complete in the elderly patients than in adults (4). $\mathrm{AKI}$ is a reality in our daily practice.

\section{Objectives}

Our study aims to compare the profile of AKI in the young patients with that of the elderly patients in order to describe the features.

\section{Patients and Methods}

\section{Patients}

We analyzed the cohort of patients hospitalized for AKI in the period from January 2010 to December 2015. It is therefore a prospective study which involved 214 cases of AKI distributed in two groups, one of young patients (aged 35 years at the most) and the other of the elderly (65 years at least). This study was carried out in the Nephrology Internal-Medicine Department at the University Hospital of Treichville. This department consists of a consulting unit, a support unit for human immunodeficiency virus (HIV), infected patients and a conventional hospitalization unit.

\section{Definitions}

AKI was defined and classified according to the Kidney Disease: Improving Global Outcomes (KDIGO) recommendations (7) on the basis of serum creatinine values determined in hospitalization. We excluded from the analysis, all patients without normal serum creatinine within 3 months prior to hospitalization.

AKI has been grouped into three stages according to KDIGO classification (7); stage 1 for a serum creatinine less than $3 \mathrm{mg} / \mathrm{dL}$ stage 2 between 3 and $4.4 \mathrm{mg} / \mathrm{dL}$ and stage 3 for a serum creatinine higher than $4.4 \mathrm{mg} / \mathrm{dL}$. Anemia is defined for a hemoglobin level below $12 \mathrm{~g} / \mathrm{dL}$. It was said severe for a hemoglobin level below $8 \mathrm{~g} / \mathrm{dL}$. Diabetes mellitus and hypertension were diagnosed according to the criteria of the World Health Organization (WHO) $(8,9)$. Patients with cancer including those having a solid or hematopoietic malignant tumor, sepsis was diagnosed in accordance with the consensus of "the American College of Chest Physicians and the Society of Critical Care Medicine Consensus" (10). HIV infection was detected by a quick test and confirmed by ELISA test in the laboratory. It was then classified in AIDS stage according to the classification of the Center for Disease Control and Prevention (CDC) (11).

$\mathrm{AKI}$ is assumed to be functional in the presence of a factor of renal hypoperfusion (diarrhea, vomiting and lowcardiac output) or in the presence of extracellular signs of dehydration. It is obstructive in the presence of AKI associated with bilateral dilatation of pyelocalyceal cavities on ultrasound scan. Acute tubular necrosis has been raised in the presence of AKI associated with proteinuria less than $1 \mathrm{~g} / 24$ hours with or without oliguria. Oliguria is defined by a diuresis less than $500 \mathrm{~mL} / 24$ hours. Acute glomerulonephritis is retained in the presence of edema, hypertension, and positive albuminuria with a decrease in the fraction of $\mathrm{C} 3$ complement. Acute interstitial nephritis is suggested in the presence of AKI with positive leukocyturia and preserved diuresis ( 1 to $2 \mathrm{~L} / \mathrm{d}$ ) or in the presence of AKI with preserved diuresis kept in a context of proven drug intake. Renal biopsy was not performed.

\section{Variables}

The measurement of serum creatinine and blood urea was performed on admission of patients. For each patient enrolled, we collected the following information using a standardized survey form; demographic data (age, gender), co-morbidities (diabetes mellitus, hypertension and HIV infection). The causes of AKI such as sepsis, water loss, and benign tumors of the urinary tract, cancer and also administration of nephrotoxic drugs were analyzed.

Clinical data (reason for admission, blood pressure on admission, temperature, level of consciousness, state of hydration, diuresis and CDC classification of HIV infection), laboratory data (serum creatinine, blood urea, serum calcium, blood glucose, hemoglobin, leukocyte count and formula, platelets count, urinalysis, blood culture, HIV status, lymphocyte CD4 count) and imaging data (renal ultrasound) were also analyzed.

Each patient has had a mean follow-up of 12 weeks. A regular determination of serum creatinine and in particular to three months allowed to assess the evolution in AKI. This evolution has been said favorable if serum creatinine was less than $1.5 \mathrm{mg} / \mathrm{dL}$ or when we observed a decrease of $50 \%$ compared with the baseline creatinine. We also analyzed serum creatinine in the last 48 hours before the death of patients.

\section{Ethical issues}

The research followed the tenets of the Declaration of Helsinki; informed consent was obtained; and the research was approved by the ethical committee of Felix HouphouetBoigny University of Medical Sciences. Participants were informed of the purpose of the study and were assured that data confidentiality would be maintained. They were also informed that the results of their examinations will be used in this study. In the context of this in-patient cohort study, the verbal consent of all participants was obtained before data collection. 


\section{Statistical analysis}

Data were processed into an Excel database and analyzed using SPSS software version 22 . We performed a bivariate analysis. The proportions of qualitative variables were compared between the young and elderly subjects by a chisquare test or a Fisher's exact test. Regarding quantitative variables, the averages were compared by Search Results Image result for analysis of variance (ANOVA) test. Quantitative variables were transformed into categorical variables according to pathological standards. Qualitative or categorical variables with $P<0.05$ were included in a binary logistic regression model to highlight the association between these variables and AKI. The association is assessed by the odds ratio (OR). The $P<0.05$ threshold was considered significant.

\section{Results}

Our study involved 106 young patients and 108 elderly patients, all presented AKI. The mean age of patients was $26.8 \pm 6$ years in the young and $69.4 \pm 7$ years in the elderly. The proportion of males was $51.9 \%$ in the young patients against $77.8 \%$ in the elderly patients $(P=0.001)$. The proportion of hypertension and diabetes in the elderly patients, respectively $30.6 \%$ and $36.1 \%$ was statistically higher than in the young patients $(P=0.001)$. However, HIV infection was more common in the young patients $(P=0.001$; Table 1$)$.

Biologically, anemia was observed in $84.9 \%$ among the young subjects against $58.3 \%$ among the elderly patients $(P=0.001)$. It was severe in $34 \%$ among the young subjects against $15.7 \%$ among the elderly patients $(P=0.002$; Table
$1)$.

The main etiologies of AKI in the young patients were in descending order, infections (56.6\%), medications (17\%) and water loss $(10.4 \%)$. In the elderly patients, infections $(47.2 \%)$, benign tumors of the urinary tract $(16.7 \%)$, malignant hypertension $(8.3 \%)$, decompensated heart disease $(8.3 \%)$ and cancer $(8.3 \%)$ were observed. The proportion of drug-induced AKI was $17 \%$ in the young patients against $2.8 \%$ in the elderly patients $(P=0.0001)$. Malignant hypertension $(P=0.002)$ and urinary tract tumors $(P=0.001)$ were more observed in the elderly patients (Table 1 ).

Among the types of infection, malaria was observed only in the young adults in $11.2 \%(P=0.001)$. In the other cases, we have not found significant differences in both groups (Table 2).

Mortality was $31.1 \%$ in the young patients against $47.2 \%$ in the elderly patients $(P=0.011)$. Survival was statistically different between groups ( $P=0.027$; Figure 1$)$. The main causes of death were respectively severe sepsis (33.3\%) and end-stage kidney disease (18.2\%) in the young subjects against severe sepsis (23.5\%), cancer (23.5\%) and stroke $(17.6 \%)$ in the elderly patients (Table 3 ). In multivariate analysis, severe sepsis appears to be the factor associated with mortality in the young patients with AKI $(P=0.027$; $\mathrm{OR}[\mathrm{CI}]=5.18$ [1.21-22.22]). Factors such as HIV positive status $(P=0.003$; OR $[\mathrm{CI}]=2.29[1.83$ to 2.86$])$ and severe sepsis $(P=0.015$; OR $[\mathrm{CI}]=3.96[2.08$ to 7.18$])$ were associated with death among the elderly patients (Table 4 ). Renal function was not fully recovered in $31.1 \%$ among the young subjects against $68.2 \%$ among the elderly patients

Table 1. General features of patients with acute kidney injury

\begin{tabular}{|c|c|c|c|c|}
\hline Features & $\leq 35$ years $(n=106)$ & $\geq 65$ years $(n=108)$ & $P$ value & OR $(95 \% \mathrm{CI})$ \\
\hline Male gender & $51.9 \%(55 / 106)$ & $77.8 \%(84 / 108)$ & 0.0001 & $1.88(1.32-2.69)$ \\
\hline \multicolumn{5}{|l|}{ Co-morbidities } \\
\hline Hypertension & $8.5 \%(9 / 106)$ & $30.6 \%(33 / 108)$ & 0.0001 & $1.80(1.42-2.27)$ \\
\hline Diabetes & $0 \%$ & $36.1 \%(39 / 108)$ & 0.0001 & $2.53(2.11-3.04)$ \\
\hline HIV & $43.4 \%(46 / 106)$ & $6.5 \%(7 / 108)$ & 0.0001 & $2.32(1.85-2.92)$ \\
\hline \multicolumn{5}{|l|}{ AKI Stage } \\
\hline Stage 1 & $29.2 \%(31 / 106)$ & $25 \%(27 / 108)$ & 0.29 & $1.11(0.83-1.48)$ \\
\hline Stage 2 & $7.5 \%(8 / 106)$ & $19.4 \%(21 / 108)$ & 0.009 & $1.54(1.17-2.02)$ \\
\hline Stage 3 & $63.2 \%(67 / 106)$ & $55.6 \%(60 / 108)$ & 0.15 & $1.17(0.88-1.56$ \\
\hline Anemia & $84.9 \%(90 / 106)$ & $58.3 \%(63 / 108)$ & 0.0001 & $2.24(1.44-3.48)$ \\
\hline Severe Anemia & $34 \%(36 / 106)$ & $15.7 \%(17 / 108)$ & 0.002 & $1.56(1.21-2.01)$ \\
\hline \multicolumn{5}{|l|}{ Etiologies } \\
\hline Decompensated heart disease & $2.8 \%(3 / 106)$ & $8.3 \%(9 / 108)$ & 0.25 & $1.34(0.82-2.17)$ \\
\hline Water loss & $10.4 \%(11 / 106)$ & $5.6 \%(6 / 108)$ & 0.14 & $1.34(0.91-1.96)$ \\
\hline Malignant hypertension & $0 \%$ & $8.3 \%(9 / 108)$ & 0.002 & $2.07(1.79-2.38)$ \\
\hline Infections & $56.6 \%(60 / 106)$ & $47.2 \%(51 / 108)$ & 0.108 & $1.21(0.91-1.59)$ \\
\hline Drugs & $17 \%(18 / 106)$ & $2.8 \%(3 / 108)$ & 0.0001 & $1.88(1.48-2.37)$ \\
\hline Benign tumors of urinary tract & $0.9 \%(1 / 106)$ & $16.7 \%(18 / 108)$ & 0.0001 & $2.05(1.70-2.47)$ \\
\hline Cancers & $3.8 \%(4 / 106)$ & $8.3 \%(9 / 108)$ & 0.13 & $1.40(0.95-2.07)$ \\
\hline Others & $8.5 \%(9 / 106)$ & $5.6 \%(6 / 108)$ & 0.28 & $1.23(0.79-1.90)$ \\
\hline Mortality & $31.1 \%(33 / 106)$ & $47.2 \%(51 / 108)$ & 0.011 & $1.38(1.06-1.79)$ \\
\hline Non recovery of renal function & $31.8 \%(28 / 106)$ & $68.2 \%(60 / 108)$ & 0.0001 & $1.65(1.30-2.10)$ \\
\hline
\end{tabular}

Abbreviation: Human immunodeficiency virus. 
Yao KH et al

Table 2. Distribution by type of infection

\begin{tabular}{|c|c|c|c|c|}
\hline Type of infection & $\leq 35$ years $(n=60)$ & $\geq 65$ years $(n=51)$ & $P$ value & OR (95\% Cl) \\
\hline Acute pyelonephritis & $5.7 \%(6 / 106)$ & $11.1 \%(12 / 108)$ & 0.11 & $1.36(0.95-1.94)$ \\
\hline Infectious diarrhea & $2.8 \%(3 / 106)$ & $8.3 \%(9 / 108)$ & 0.07 & $1.53(1.07-2.18)$ \\
\hline Pleuropneumopathy & $11.3 \%(12 / 106)$ & $5.6 \%(6 / 108)$ & 0.10 & 1.39 (0.97-1.98) \\
\hline Severe sepsis & $14.2 \%(15 / 106)$ & $19.4 \%(21 / 108)$ & 0.19 & 1.19 (0.87-1.63) \\
\hline Malaria & $11.3 \%(12 / 106)$ & $0 \%$ & 0.0001 & $2.14(1.85-2.49)$ \\
\hline Other infections & $8.5 \%(9 / 106)$ & $2.7 \%(3 / 108)$ & 0.06 & $1.56(1.09-2.23)$ \\
\hline
\end{tabular}

Table 3. Distribution of patients by cause of death

\begin{tabular}{lcccc}
\hline \multirow{2}{*}{ Parameters } & \multicolumn{5}{c}{ Cause of death* } \\
\cline { 2 - 5 } & \multicolumn{3}{c}{$\leq 35$ years } & \multicolumn{2}{c}{$\geq 65$ years } \\
\cline { 2 - 5 } & No. $(\mathbf{n}=\mathbf{3 3})$ & $\mathbf{( \% )}$ & No. (n=51) & $(\%)$ \\
\hline Stroke & - & - & 09 & $(17.6)$ \\
Cancer & 03 & $(09)$ & 12 & $(23.5)$ \\
Heart disease & - & - & 03 & $(05.8)$ \\
Pulmonary embolism & 01 & $(03)$ & - & - \\
Hepatic failure & 03 & $(09)$ & 06 & $(11.7)$ \\
End-stage renal disease & 06 & $(18.2)$ & 02 & $(3.9)$ \\
Lymphoma & - & - & 01 & $(1.9)$ \\
Severe sepsis & 11 & $(33.3)$ & 12 & $(23.5)$ \\
Hemolytic and uremic & 03 & $(09)$ & - & - \\
Syndrome & 03 & $(09)$ & 03 & $(05.8)$ \\
AIDS & 03 & $(09)$ & 03 & $(05.8)$ \\
\hline Tuberculosis & & & & \\
\hline
\end{tabular}

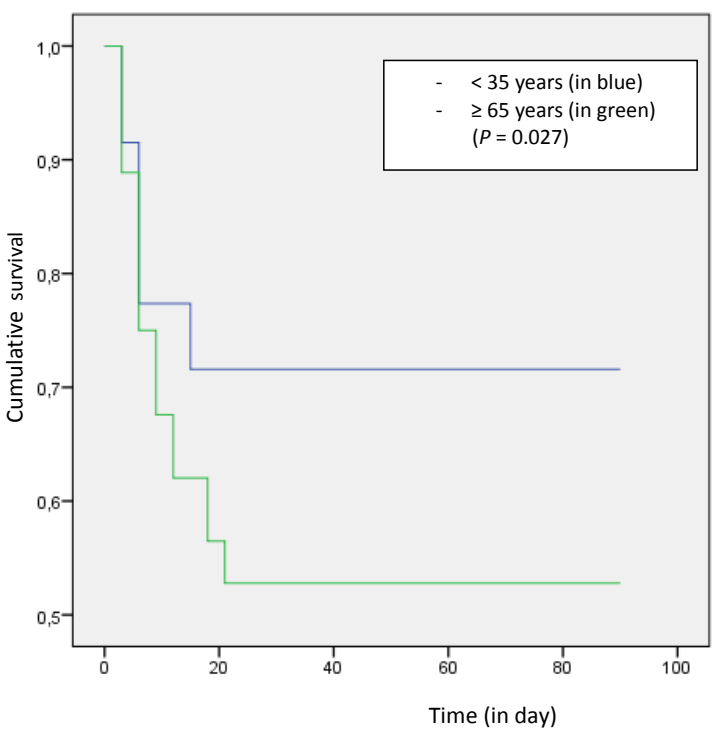

Figure 1. Cumulative survival curve

$(P=0.0001 ;$ OR $[C I]=1.65[1.30-2.10])($ Table 1$)$. Anemia was associated with non-recovery of renal function in the young patients $(P=0.016$; OR $[\mathrm{CI}]=1.79$ [1.08-2.98]). In the elderly patients, factors such as hypertension $(P=0.014$; OR $[\mathrm{CI}]=3.16[1.26-7.92])$, coma $(P=0.0001$, OR $[C I]=7.77[2.73-22.14])$ and cancer $(P=0.009$; OR $[\mathrm{CI}]=2.36[1.48-3.76])$ were associated with the nonrecovery of renal function during AKI (Table 5).

\section{Discussion}

The risk of occurrence of AKI is determined by factors related to patients, including advanced age, CKD and other underlying chronic conditions, and exhibitions such as sepsis, surgery and nephrotoxic drugs (12-14).

The male predominance is observed in several studies $(15,16)$ as in ours and can be explained by the predominance of males in the general population. AKI is a common reason for admission in intensive care unit (ICU) and its incidence increases with age (17).

Infections, toxics and obstetric gynecological pathologies are the main causes of AKI in African series (6). According to Baraldi et al, drugs (35.7\%) and renal hypoperfusion $(30.2 \%)$ are the main etiologies in the West. In Italy, renal hypoperfusion (38\%) and sepsis are the most observed (18). Other authors have found septic shock, hyopovolemia, cardiogenic shock and post-operative AKI as the major causes of AKI in adults in the West countries (4).

The causes of AKI in the elderly patients are not different from those of the general population in the West countries (19). In our study, infections, obstructive nephropathy, and functional AKI are the most observed in the elderly patients. Prostatic hyperplasia affects $50 \%$ of men over 50 and $90 \%$ of men over 90 years (20). Similarly, the incidence of cancer pathology of the pelvis increases with age (21). It should also be underlined a significant proportion of AKI due to malignant hypertension in the elderly patients that could be explained by the fact that medical care are out of reach of our patients.

In our study, drug-induced AKI is significantly more frequent in the younger patients compared with the elderly patients. Drug-induced AKI which accounts for only $2.8 \%$ of the causes of AKI in the elderly patients in our work, is a major cause of AKI in the West countries, up to $44.9 \%$ depending on the authors $(16,18)$. Some authors emphasize the growing part of iatrogenic as a risk factor for AKI in the elderly, frequently exposed to polypharmacy $(19,22)$.

Regarding the type of infection, all AKI cases by malaria were observed in the young patients. The impact of AKI during malaria varies in the order of 15 to $48 \%$ according to studies (23). This variation could depend on the age of patients and the anti-malarial immunity, which are in their turn influenced by the intensity of malaria transmission (24). This anti-malarial immunity could explain the absence of AKI cases by malaria in the elderly patients in 
Table 4. Death risk factors

\begin{tabular}{|c|c|c|c|c|}
\hline \multirow{2}{*}{ Variables } & \multirow{2}{*}{$P$ value } & \multirow{2}{*}{ OR } & \multicolumn{2}{|c|}{$95 \% \mathrm{Cl}$} \\
\hline & & & Inferior & Superior \\
\hline \multicolumn{5}{|l|}{$\leq 35$ years } \\
\hline Female gender & 0.052 & & & \\
\hline Severe sepsis & 0.027 & 5.18 & 1.21 & 22.22 \\
\hline \multicolumn{5}{|l|}{$\geq 65$ years } \\
\hline HIV positive & 0.003 & 2.29 & 1.83 & 2.86 \\
\hline Severe sepsis & 0.015 & 3.87 & 2.08 & 7.18 \\
\hline Cancer & 0.999 & - & - & - \\
\hline
\end{tabular}

Table 5. Risk factors of non recovery of renal function

\begin{tabular}{|c|c|c|c|c|}
\hline \multirow{2}{*}{ Variables } & \multirow{2}{*}{$P$ value } & \multirow{2}{*}{ OR } & \multicolumn{2}{|l|}{$95 \% \mathrm{Cl}$} \\
\hline & & & Inferior & Superior \\
\hline \multicolumn{5}{|l|}{$\leq 35$ years } \\
\hline Anemia & 0.016 & 1.79 & 1.08 & 2.98 \\
\hline Cancer & 0.99 & - & - & - \\
\hline \multicolumn{5}{|l|}{$\geq 65$ years } \\
\hline Hypertension & 0.014 & 3.16 & 1.26 & 7.92 \\
\hline Coma & 0.0001 & 7.77 & 2.73 & 22.14 \\
\hline Cancer & 0.009 & 2.36 & 1.48 & 3.76 \\
\hline
\end{tabular}

our study. AKI during malaria is considered as a disease primarily of adults and older children (25).

The lethality is high during AKI, in the order of $32 \%$ according to African data (6). This mortality varies from $21.9 \%$ to $67.3 \%$ depending on the series (26-28). For patients with severe AKI, it is from $51 \%$ to 28 days and $60 \%$ to three months (29).

Severe sepsis was a death risk factor common to both groups. In the elderly patients, HIV positive status also seems to favor death. In the study of Liaño et al, mortality factors were coma, respiratory support, hypotension and oliguria (17). For others, factors such as the presence of neoplasia, heart or liver disease, sepsis and oliguria are of poor prognosis (30). Prognosis for life depends more on the severity of the disease causing AKI than its consequences (31).

As for renal survival, recovery of renal function seems slower and less complete in the elderly patients than in adults $(32,33)$. A meta-analysis revealed that $31 \%$ of elderly patients could not recover renal function after an episode of AKI compared with $26 \%$ of younger patients (34). The largest proportion in our study could be explained by the delay in the management of our patients related to the precarious socio-economic conditions of these and the lack of social security system. Factors such as sepsis, hypertension and cancer seem associated with the non recovery of renal function during AKI $(35,36)$.

\section{Conclusion}

The etiologies are the same with different proportions, except malignant hypertension observed only in the elderly patients. The drug causes are more common in young. Mortality is higher in the elderly patients and the non-recovery of renal function was significantly greater in this group. An early management could help improve the vital and functional renal prognosis.

Limitations of the study

The small number and low socio-economic status of patients, the single-center nature are the limitations of our study. Additional tests have not been systematically carried out in time for all patients.

Acknowledgments

We thank the staff of the department of nephrologyinternal medicine of the university hospital of Treichville for their participation in the study. We also thank Mr. KAHAN $\mathrm{P}$ for translation.

\section{Authors' contribution}

KHY has made a substantial contribution to conception and design, analysis and interpretation of data. He has also been involved in drafting the manuscript and revising it critically for important intellectual content. GMC, KSD and DSP have collected data. WMT and SS have revised the manuscript critically for important intellectual content.

\section{Conflict of interests}

The authors declare no conflict of interest.

Ethical considerations

Ethical issues (including plagiarism, data fabrication, double publication) have been completely observed by the authors.

\section{Funding/Support}

No funding was received for this study.

\section{References}

1. Fang Y, Ding X, Zhong Y, Zou J, Teng J, Tang Y, Lin J, Lin P. Acute kidney injury in a Chinese hospitalized population. Blood Purif. 2010;30:120-6. doi:10.1159/000319972.

2. Lafrance JP, Miller DR. Acute kidney injury associates with increased long-term mortality. J Am Soc Nephrol. 2010;21:345-52. doi: 10.1681/ASN.2009060636.

3. Li PK, Burdmann EA, Mehta RL. World Kidney Day 2013: acute kidney injury-global health alert. Am J Kidney Dis. 2013;61:359-63. doi: 10.1053/j.ajkd.2013.01.002.

4. Mehta RL, Cerdá J, Burdmann EA, Tonelli M, García-García $\mathrm{G}$, Jha V, et al. International Society of Nephrology's 0 by 25 initiative for acute kidney injury (zero preventable deaths by 2025): a human rights case for nephrology. Lancet. 2015;385:2616-43. doi: 10.1016/S0140-6736(15)60126-X.

5. Lameire NH, Bagga A, Cruz D, De Maeseneer J, Endre Z, Kellum JA. Acute kidney injury: an increasing global concern. Lancet. 2013;382:170-9. doi: 10.1016/S01406736(13)60647-9.

6. Olowu WA, Niang A, Osafo C, Ashuntantang G, Arogundade FA, Porter J. Outcomes of acute kidney injury in children and adults in sub-Saharan Africa: a systematic review. Lancet Glob Health 2016;4:e242-50.

7. Kidney Disease: Improving Global Outcomes (KDIGO) 
Work Group. KDIGO clinical practice guideline for acute kidney injury. Kidney Int Suppl. 2012;2:1-138. doi:10.1038/ kisup.2012.73.

8. Alberti KG, Zimmet PZ. Definition, diagnosis and classification of diabetes mellitus and its complications. Part 1: diagnosis and classification of diabetes mellitus provisional report of a WHO consultation. Diabet Med 1998;15:539-53.

9. Chalmers J, MacMahon S, Mancia G, Whitworth J, Beilin L, Hansson L, et al. 1999 World Health OrganizationInternational Society of Hypertension Guidelines for the management of hypertension. Guidelines sub-committee of the World Health Organization. Clin Exp Hypertens. 1999;21:1009-60.

10. Levy MM, Fink MP, Marshall JC, Abraham E, Angus D, Cook D, et al. 2001 SCCM/ESICM/ACCP/ ATS/SIS International Sepsis Definitions Conference. Crit Care Med 2003;31:1250-6.

11. Pascual J, Orofino L, Liano F, Marcen R, Naya MT, Orte L, et al. Incidence and prognosis of acute renal failure in older patients. J Am Geriatr Soc. 1990;38:25-30.

12. Bellomo R, Ronco C, Kellum JA, Mehta RL, Palevsky P; Acute Dialysis Quality Initiative Workgroup. Acute renal failure-definition, outcome measures, animal models, fluid therapy and information technology needs: the Second International Consensus Conference of the Acute Dialysis Quality Initiative (ADQI) Group. Crit Care. 2004;8:R20412.

13. Kamps BS, Brodt HR, Staszewski S, Bergmann L, Helm EB. AIDS-free survival and overall survival in HIV infection: the new CDC classification system (1993) for HIV disease and AIDS. Clin Investig. 1994;72:283-7.

14. Cartin-Ceba R, Kashiouris M, Plataki M, Kor DJ, Gajic O, Casey ET. Risk factors for development of acute kidney injury in critically ill patients: a systematic review and meta-analysis of observational studies. Crit Care Res Pract. 2012;69:10-3. doi: 10.1155/2012/691013.

15. Feest TG, Round A, Hamad S. Incidence of severe acute renal failure in adults: results of a community based study. BMJ. 1993;306:481-3.

16. Kane-Gill SL, Sileanu FE, Murugan R, Trietley GS, Handler SM, Kellum JA. Risk factors for acute kidney injury in older adults with critical illness: a retrospective cohort study. Am J Kidney Dis. 2015;65:860-9. doi: 10.1053/j.ajkd.2014.10.018.

17. Liaño F, Pascual J. Epidemiology of acute renal failure: a prospective, multicenter, community-based study. Madrid Acute Renal Failure Study Group. Kidney Int 1996;50:8118.

18. Baraldi $\mathrm{A}$, Ballestri $\mathrm{M}$, Rapanà $\mathrm{R}$, Lucchi L, Borella $\mathrm{P}$, Leonelli $\mathrm{M}$, et al. Acute renal failure of medical type in an elderly population. Nephrol Dial Transplant. 1998;13:25-9.

19. Lautrette A, Heng AE, Jaubert D, Hssain AA, Deteix P, Souweine B. Insuffisance rénale aiguë du sujet âgé. Nephrol Ther 2012;8:57-62.

20. Coffey DS, Walsh PC. Clinical and experimental studies of benign prostatic hyperplasia. Urol Clin North Am. 1990; 17:461-75.
21. Klahr S, Chandhoke P, Clayman RV. Obstructive uropathy: renal effects and endosurgical relief. J Endourol. 1993; 7:395-8.

22. Mac K, Chavada R, Paull S, Howlin K, Wong J. Cefepime induced acute interstitial nephritis - a case report. BMC Nephrol. 2015;16:15. doi: 10.1186/s12882-015-0004-x.

23. Chellappan A, Bhadauria DS. Acute kidney injury in malaria: an update. Clinical Queries: Nephrology. 2016 5:26-32. doi: 10.1016/j.cqn.2016.04.004.

24. Mishra SK, Das BS. Malaria and Acute Kidney Injury. Semin Nephrol. 2008;28:395-408. doi: 10.1016/j. semnephrol.2008.04.007.

25. WHO. Severe falciparum malaria. Trans R Soc Trop Med Hyg. 2000;94 Suppl 1:s1-90.

26. Barsoum RS. Malaria acute renal failure. J Am Soc Nephrol. 2000; 11:2147-54.

27. Neveu H, Kleinknecht D, Brivet F, Loirat P, Landais P. Prognostic factors in acute renal failure due to sepsis. Results of a prospective multicentre study. The French Study Group on Acute Renal Failure. Nephrol Dial Transplant. 1996;11:293-9.

28. McClure M, Singh GJ, Rayment M, Jones R, Levy JB. Clinical outcomes of a combined HIV and renal clinic. Clin Kidney J. 2012;5:530-4. doi: 10.1093/ckj/sfs141.

29. Lu R, Mucino-Bermejo MJ, Armignacco P, Fang Y, Cai H, Zhang M, et al. Survey of acute kidney injury and related risk factors of mortality in hospitalized patients in a thirdlevel urban hospital of Shanghai. Blood Purif. 2014;38:1408. doi: 10.1159/000366127.

30. Cruz DN, Bolgan I, Perazella MA, Bonello M, de Cal M, Corradi V, et al. North east italian prospective hospital renal outcome survey on acute kidney injury (NEiPHROS-AKI): targeting the problem with the RIFLE criteria. Clin J Am Soc Nephrol. 2007;2:418-25. doi: 10.2215/CJN.03361006.

31. Sesso R, Roque A, Vicioso B, Stella S. Prognosis of ARF in hospitalized elderly patients. Am J Kidney Dis. 2004 Sep;44:410-9.

32. Santacruz F, Barreto S, Mayor MM, Cabrera W, Breuer N. Mortality in elderly patients with acute renal failure. Ren Fail. 1996;18:601-5.

33. Gentric A, Cledes J. Immediate and long-term prognosis in acute renal failure in the elderly. Nephrol Dial Transplant. 1991;6:86-90.

34. Schmitt R, Coca S, Kanbay M, Tinetti ME, Cantley LG, Parikh CR. Recovery of kidney function after acute kidney injury in the elderly: A systematic review and metaanalysis. Am J Kidney Dis 2008;52:262-71. doi: 10.1053/j. ajkd.2008.03.005.

35. Hamzić-Mehmedbašić $A$, Rašić $S$, Balavac M, Rebić D, Delić-Šarac M, Durak-Nalbantić A. Prognostic indicators of adverse renal outcome and death in acute kidney injury hospital survivors. J Renal Inj Prev. 2016;5:61-8. doi: 10.15171/jrip.2016.14.

36. Shiao CC, Wu PC3, Huang TM4, Lai TS5, Yang WS6, Wu $\mathrm{CH}$, et al. Long-term remote organ consequences following acute kidney injury. Crit Care 2015;19:438. doi: 10.1186/ s13054-015-1149-5.

Copyright (C) 2017 The Author(s); Published by Nickan Research Institute. This is an open-access article distributed under the terms of the Creative Commons Attribution License (http://creativecommons.org/licenses/by/4.0), which permits unrestricted use, distribution, and reproduction in any medium, provided the original work is properly cited. 